\title{
Alocação de compostos nitrogenados de reserva durante a germinação de sementes de Canavalia brasiliensis
}

\author{
Liliane Santos Camargos ${ }^{1 *}$ \\ Caroline Regazini de Sá Soares ${ }^{2}$ \\ Gilberto Costa Justino $^{3}$ \\ Leandro Ferreira Aguiar ${ }^{2}$ \\ ${ }^{1}$ Universidade Estadual Paulista, Faculdade de Engenharia de Ilha Solteira \\ Avenida Brasil, 56, Centro, CEP 15385-000, Ilha Solteira - SP, Brasil \\ ${ }^{2}$ Universidade Federal de Mato Grosso do Sul, Campus de Três Lagoas \\ Avenida Ranulpho Marques Leal, 3484, Distrito Industrial, CEP 79601-100, Três Lagoas - MS, Brasil \\ ${ }^{3}$ Universidade Federal de Alagoas, Campus de Maceió, Instituto de Ciências Biológicas e da Saúde \\ CEP 57010-020, Maceió - AL, Brasil \\ * Autor para correspondência \\ camargos@bio.feis.unesp.br
}

Submetido em 03/04/2013

Aceito para publicação em 30/09/2013

\section{Resumo}

Canavalia brasiliensis, vulgarmente conhecida como feijão-bravo-do-ceará, é uma planta herbácea com grande potencial de produção de biomassa e rusticidade durante o período de baixa disponibilidade hídrica, aliado à grande eficiência de fixação de nitrogênio. O objetivo deste artigo foi avaliar os principais compostos nitrogenados e a translocação deles dos tecidos de reserva (cotilédones) para a plântula durante e após a germinação. Para tanto, o experimento foi conduzido em câmara de germinação, sendo as plântulas mantidas em vasos de $4 \mathrm{~L}$ contendo vermiculita durante todo o período experimental. As plântulas foram coletadas em intervalos de dois dias até a senescência e abscisão dos cotilédones, que se deu 16 dias após a germinação (protrusão da radícula). Em cada uma das épocas de coleta, as plântulas foram separadas em raízes, caule, folhas e cotilédones e, em triplicata, foram analisados o conteúdo de proteínas totais, aminoácidos solúveis totais, canavanina, ureídeos (alantoína e ácido alantoico) e nitrato em todos os tecidos. Observou-se redução nos níveis de canavanina e proteína total à medida que se aumentou o período de coleta, com o desaparecimento dos níveis de canavanina após 16 dias. Proteínas e aminoácidos apresentaram concentrações inversamente proporcionais, ou seja, ocorrendo o aumento de um ocorreu diminuição do outro até a senescência e abscisão dos cotilédones. Detectou-se presença de nitrato nos tecidos das plântulas até a última coleta (16 dias após a germinação). A concentração de ureídeos (ácido alantoico e alantoína) foi elevada durante todo o período avaliado, indicando serem componentes do metabolismo de nitrogênio de C. brasiliensis, ocorrendo síntese de novo.

Palavras-chave: Compostos de reserva; Feijão-bravo; Nitrogênio; Ureídeos

\section{Abstract}

Allocation of reserve nitrogen compounds during germination of Canavalia brasiliensis seeds. Canavalia brasiliensis, commonly known as "feijão-bravo-do-ceará", is an herbaceous plant with a great 
potential for biomass production and rusticity within the period of low water availability, coupled with the great effectiveness of nitrogen fixation. This article aims to evaluate the main nitrogen compounds and their translocation from seed to seedling during and after germination. For this, the experiment was conducted in a germination chamber, and seedlings were kept in $4 \mathrm{~L}$ pots containing vermiculite throughout the experimental period. Seedlings were collected every 2 days until the senescence and abscission of cotyledons, which took place 16 days after germination (radicle protrusion). In each of the collection times, we divided seedlings into roots, stem, leaves, and cotyledons and analyzed, three times, the total protein, total soluble amino acids, canavanine, ureides (allantoin and allantoic acid), and nitrate contents in all tissues. We observed a decrease in the canavanine and total protein levels as the collection period was increased, and the canavanine levels disappeared after 16 days. Proteins and amino acids showed inversely proportional concentrations, i.e. whenever one increases the other decreases until the senescence and abscission of cotyledons. We detected the presence of nitrate in the seedling tissues until the last collection (16 days after germination). The concentration of ureides (allantoic acid and allantoin) was high throughout the evaluated period, indicating that they are compounds for nitrogen metabolism in C. brasiliensis, and there is de novo synthesis.

Key words: "Feijão-bravo"; Nitrogen; Reserve compounds; Ureides

\section{Introdução}

As reservas de carboidratos, lipídios e proteínas presentes nas sementes são utilizadas pelo eixo embrionário como fonte de energia e substrato para estruturas celulares. A mobilização de reservas durante a germinação é o ponto crucial do estabelecimento da plântula, com o aporte para a formação da estrutura básica do corpo vegetal e síntese de intermediários metabólicos com finalidades diversas. Essas reservas são mobilizadas durante a germinação, e no decorrer do desenvolvimento das plântulas seus produtos de degradação são usados para diferentes propósitos, como a geração de energia e a produção de matéria-prima para a construção de novas células e tecidos. Neste contexto, carboidratos e lipídios atuam como fonte de energia e de carbono, essenciais para a germinação, crescimento e desenvolvimento da plântula. Por outro lado, proteínas são importantes como fontes de enxofre e nitrogênio $(\mathrm{N})$, fundamentais para a síntese de novas proteínas, ácidos nucleicos e compostos secundários necessários ao desenvolvimento da plântula (BUCKERIDGE et al., 2000). O sucesso do estabelecimento da espécie vegetal depende fortemente do adequado processo de utilização das reservas da semente, sendo que estes mecanismos funcionais são cruciais para a manutenção e desenvolvimento do embrião até a formação do organismo autótrofo (BUCKERIDGE et al., 2004).
O nitrogênio $(\mathrm{N})$ é o elemento mais extensivamente assimilado do solo pelas plantas superiores e o metabolismo deste elemento é um processo essencial, necessário para a biossíntese de biomoléculas tais como aminoácidos (proteínas), nucleotídeos (ácidos nucleicos), clorofila e outros metabólitos contendo $\mathrm{N}$ (LAM et al., 2006).

A disponibilidade de $\mathrm{N}$ é um fator que limita o crescimento e a produtividade vegetal mais do que qualquer outro fator nutricional (VITOUSEK; HOWARTH, 1991; CRAWFORD; GLASS, 1998), o que, consequentemente, exercerá influência sobre o aporte de reservas na semente e remobilização destas reservas durante o período de germinação.

Evolutivamente, as Leguminosas através da fixação biológica obtida por meio de simbiose com bactérias do gênero Rhyzobium/Bradyrhyzobium nas raízes possuem facilidade de obtenção deste elemento e constitui em uma das principais fontes primárias de nitrogênio fixado para os diferentes ecossistemas.

A Canavalia brasiliensis é uma espécie fixadora de nitrogênio importante em programas que visam à recuperação dos teores de nitrogênio do solo, pois acumula grandes quantidades de nitrogênio, especialmente nas sementes, característica fundamental para o estabelecimento da plântula. A C. brasiliensis é também conhecida como feijão-Bravo-do-Ceará, apresenta grande potencial de produção de biomassa e rusticidade durante o período de baixa disponibilidade 
hídrica, devido ao seu sistema radicular agressivo, sendo favorecida a absorção de água e nutrientes em maiores profundidades no solo (SODRÉ-FILHO et al., 2004).

Com o objetivo de verificar as estratégias de alocação de compostos orgânicos nitrogenados de reserva durante a fase inicial do estabelecimento de plântulas de $C$. brasiliensis foram determinados durante dezesseis dias após a germinação (período em que as reservas cotiledonares se esgotam), em diferentes partes da plântula, os teores de nitrato, aminoácidos, ureídeos e proteínas.

\section{Material e Métodos}

\section{Obtenção do material}

Sementes de Canavalia brasiliensis foram cedidas pela Embrapa/CPAC e multiplicadas em Três Lagoas - MS (2045'42"; 5140’42”; 319 m) sem controle de fotoperíodo e temperatura, com temperaturas aproximadas de $18,2^{\circ} \mathrm{C}$ (mínima), no inverno, e de $36,8^{\circ} \mathrm{C}$ (máxima), no verão.

\section{Cultivo e coleta de material}

As sementes foram transferidas para vasos, com capacidade de $4 \mathrm{~L}$, com vermiculita como substrato, em câmara de germinação com temperatura controlada em $27^{\circ} \mathrm{C}$ e fotoperíodo de $12 \mathrm{~h}$, irrigadas diariamente. As plântulas foram mantidas durante 22 dias, sendo as coletas realizadas a cada dois dias, iniciando-se logo após a emergência da radícula. Assim, foram realizadas oito coletas até o estádio de senescência e abscisão dos cotilédones.

Cada coleta consistiu em três plântulas, sendo os tecidos separados (folhas cotiledonar e folha permanente, caule, cotilédone e raiz) e armazenados em freezer a $-25^{\circ} \mathrm{C}$ para as análises posteriores. Cada plântula representou uma repetição, sendo seus tecidos, individualmente, utilizados para extração e dosagem de compostos.

\section{Extração de compostos nitrogenados}

Através do método descrito em Bieleski e Turner (1966) os compostos nitrogenados foram extraídos para as análises de compostos solúveis. Para $0,5 \mathrm{~g}$ de material fresco, acrescentou-se $5 \mathrm{~mL}$ de MCW (60\% metanol, $25 \%$ clorofórmio, $15 \%$ de água; v/v/v). O material foi triturado com auxilio de um almofariz de porcelana e em seguidas centrifugados. Após a centrifugação, acrescentou-se $1 \mathrm{~mL}$ de clorofórmio $+1,5 \mathrm{~mL}$ de água, para cada $4 \mathrm{~mL}$ de sobrenadante. Aguardou-se a separação de fases e utilizou-se a fase hidrossolúvel para análise de compostos nitrogenados (aminoácidos totais, ureídeos, alantoína e ácido alantoico, e nitrato).

O precipitado foi ressuspendido em solução $\mathrm{NaOH}$ $0,1 \mathrm{M}$, a uma relação de $10 \mathrm{~mL}$ de solução para cada grama de amostra (tecido fresco); após homogeneização, a amostra foi centrifugada e o sobrenadante utilizado para quantificação de proteínas.

\section{Quantificação de compostos nitroge- nados}

O conteúdo de aminoácidos, ureídeos (alantoína e ácido alantoico), nitrato, proteína total e canavanina (aminoácido não-proteico) foram quantificados segundo a metodologia descrita em Yemm e Cocking (1955), Vogels e Van der Drift (1970), Cataldo et al. (1975), Bradford (1976) e Rosenthal (1977), respectivamente, a fim de identificar as variações na concentração de compostos presentes nos diferentes tecidos da leguminosa durante o período de germinação e partição de reservas.

\section{Delineamento experimental}

Para o experimento foi utilizado o delineamento inteiramente casualizado. Os resultados foram apresentados na forma de média de três repetições.

\section{Resultados}

Aos dois dias, após a germinação, foi verificada a presença de nitrato apenas em cotilédones (Tabela 1). Posteriormente, aos quatro dias, este nutriente 
TABELA 1: Variação da concentração de compostos nitrogenados em tecidos de Canavalia brasiliensis após a germinação. Os dados representam a média de três repetições. Dados expressos em: mg/g.MF (proteína), $\mu \mathrm{mol} / \mathrm{g} . \mathrm{MF}$ (aminoácidos, canavanina e nitrato).

\begin{tabular}{|c|c|c|c|c|}
\hline Dias após germinação & Proteína & Aminoácidos & Canavanina & Nitrato \\
\hline \multicolumn{5}{|l|}{2 dias } \\
\hline Folha & 14,31 & 38,84 & 5,04 & 0 \\
\hline Cotilédone & 9,04 & 47,92 & 1,14 & 1,39 \\
\hline Caule & 7,38 & 36,61 & 5,00 & 0 \\
\hline Raiz & 6,03 & 16,64 & 1,17 & 0 \\
\hline \multicolumn{5}{|l|}{4 dias } \\
\hline Folha & 11,02 & 102,00 & 3,26 & 3,45 \\
\hline Cotilédone & 10,32 & 46,90 & 0,61 & ND \\
\hline Caule & 4,35 & 80,22 & 1,01 & 2,23 \\
\hline Raiz & 3,43 & 39,08 & 4,74 & ND \\
\hline \multicolumn{5}{|l|}{6 dias } \\
\hline Folha & 6,99 & 11,62 & 20,22 & 3,85 \\
\hline Cotilédone & 4,94 & 0,35 & 11,25 & 0,90 \\
\hline Caule & 2,20 & 0,20 & 30,50 & ND \\
\hline Raiz & 2,22 & 1,15 & 1,18 & ND \\
\hline \multicolumn{5}{|l|}{8 dias } \\
\hline Folha & 7,97 & 7,55 & ND & 3,88 \\
\hline Cotilédone & 15,08 & 3,6 & ND & 7,70 \\
\hline Caule & 3,62 & 0,15 & ND & 0,80 \\
\hline Raiz & 4,16 & 1,52 & ND & 1,62 \\
\hline \multicolumn{5}{|l|}{10 dias } \\
\hline Folha & 4,84 & 77,24 & 0,71 & 3,82 \\
\hline Cotilédone & 0,02 & 0,53 & ND & ND \\
\hline Caule & 0,25 & 82,52 & ND & 21,40 \\
\hline Raiz & 2,13 & 14,29 & ND & 10,12 \\
\hline \multicolumn{5}{|l|}{12 dias } \\
\hline Folha & 5,37 & 0,07 & 2,83 & 17,34 \\
\hline Cotilédone & 8,21 & 0,31 & ND & 19,12 \\
\hline Caule & 7,66 & 0,05 & 0,94 & 0,41 \\
\hline Raiz & 6,36 & 0,21 & 1,09 & 18,46 \\
\hline \multicolumn{5}{|l|}{14 dias } \\
\hline Folha & 3,37 & 0,10 & ND & ND \\
\hline Cotilédone & 1,86 & 0,03 & ND & 1,62 \\
\hline Caule & 1,49 & 0,04 & ND & ND \\
\hline Raiz & 0,45 & 0,09 & ND & ND \\
\hline Folha & 22,69 & 1,21 & ND & ND \\
\hline \multicolumn{5}{|l|}{ Permanente } \\
\hline \multicolumn{5}{|l|}{16 dias } \\
\hline Folha & 6,52 & 0,12 & 1,63 & 3,64 \\
\hline Cotilédone & 3,75 & 0,08 & ND & 11,98 \\
\hline Caule & 3,28 & 0,09 & ND & ND \\
\hline Raiz & 2,05 & 0,20 & ND & ND \\
\hline Folha & 5,19 & 0,62 & ND & ND \\
\hline Permanente & & & & \\
\hline
\end{tabular}

* ND: não detectado. 
foi encontrado em folhas e caules e, somente, aos seis dias, após a germinação, foi verificado em raízes. No caule, aos dez dias, foram observados os maiores teores de nitrato, mas posteriormente esta quantidade decresceu, e o nutriente não foi mais detectado a partir dos 14 dias. Nas raízes, os maiores teores de nitrato foram verificados aos 12 dias, e, como observado em caule, não foi mais verificado a partir de 14 dias.

Os maiores teores de proteínas foram encontrados em cotilédones e folhas cotiledonares, permanecendo até o oitavo dia após a germinação. Aos 14 dias, foi observada a maior concentração de proteínas na folha permanente, mas estes valores reduziram aos 16 dias.

Os teores de aminoácidos foram proeminentes em cotilédones até os 4 dias após a germinação, depois os valores foram bem discretos até o final do experimento. Em folhas, os teores de aminoácidos aumentaram significativamente no quarto dia quando comparado a primeira determinação, realizada aos dois dias. Os teores de aminoácidos foram maiores em cotilédones dois dias após a germinação, mas posteriormente verificou-se um aumento nas folhas aos quatro dias. A partir deste momento, os teores de aminoácidos foliares foram superiores aos encontrados em cotilédones até o décimo dia. A partir do décimo segundo dia após a germinação, observa-se uma brusca redução nos níveis de aminoácidos até a abscisão dos cotilédones. No tecido de caule, assim como em raízes, houve um aumento nos níveis de aminoácidos no quarto dia após a germinação, com novo aumento expressivo no décimo dia, ocorrendo depois, no décimo segundo dia, uma diminuição destes níveis.

As folhas cotiledonares, cotilédones e caule apresentaram um aumento na quantidade canavanina, um aminoácido não-proteíco com função inseticida, seis dias após a germinação, mas posteriormente, este aminoácido praticamente não foi detectado ou, então, detectado em pequenas quantidades, apenas, em folhas cotiledonares e caules.

Os maiores teores de ureídeos foram verificados em folhas permanentes, a partir de quatorze dias após a germinação, quando os valores nas outras partes da plântula começaram a diminuir (Figura 1). A folha cotiledonar e as raízes apresentaram os maiores valores no segundo e no quarto dia após a germinação. Os valores continuaram proeminentes até os doze dias após a germinação. Os maiores teores de ácido alantoico foram encontrados no segundo e no quarto dia após a germinação, diminuindo a partir do sexto dia (Figura 2). Entretanto, após o surgimento da primeira folha

FIGURA 1: Variação da concentração de ureídeos totais em tecidos de Canavalia brasiliensis após a germinação. Os dados representam a média de três repetições. Dados expressos em: $\mu \mathrm{mol} / \mathrm{g}$.MF.

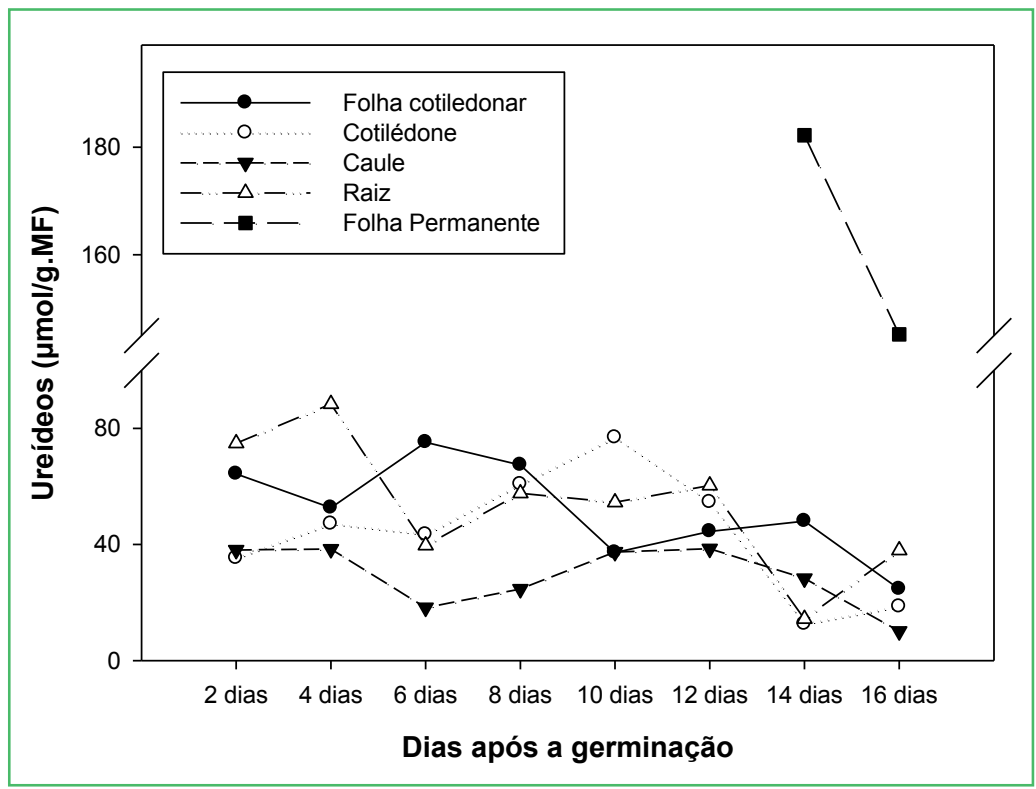


permanente foram verificados valores proeminentes novamente. Os teores de alantoína diminuíram em cotilédones, caules e raízes no quarto dia após a germinação e, posteriormente, de um modo geral estes valores começaram a aumentar nestes tecidos até o décimo segundo dia (Figura 3). No décimo quarto dia ocorreu uma redução novamente, mas acompanhada de um significativo aumento nas folhas permanentes.

FIGURA 2: Variação da concentração de ácido alantoico em tecidos de Canavalia brasiliensis após a germinação. Os dados representam a média de três repetições. Dados expressos em: $\mu \mathrm{mol} / \mathrm{g}$.MF.

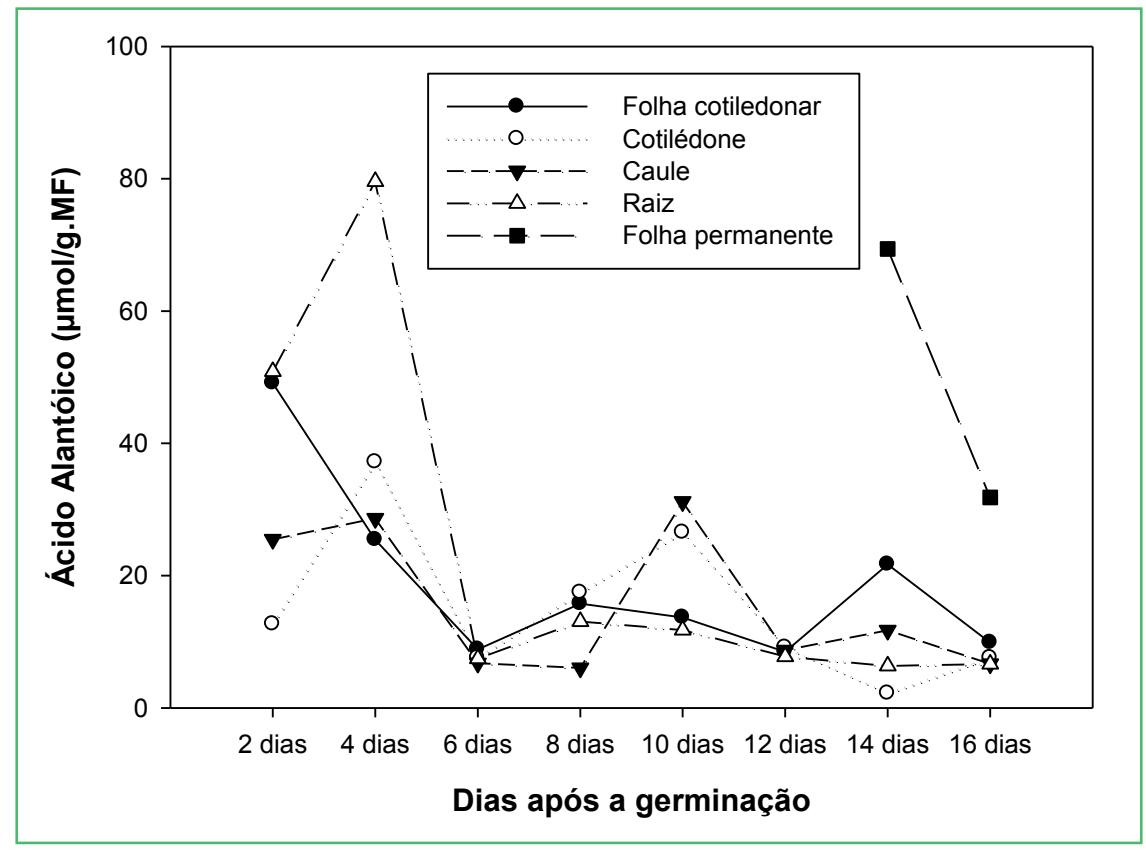

FIGURA 3: Variação da concentração de alantoína em tecidos de Canavalia brasiliensis após a germinação. Os dados representam a média de três repetições. Dados expressos em: $\mu \mathrm{mol} / \mathrm{g}$.MF.

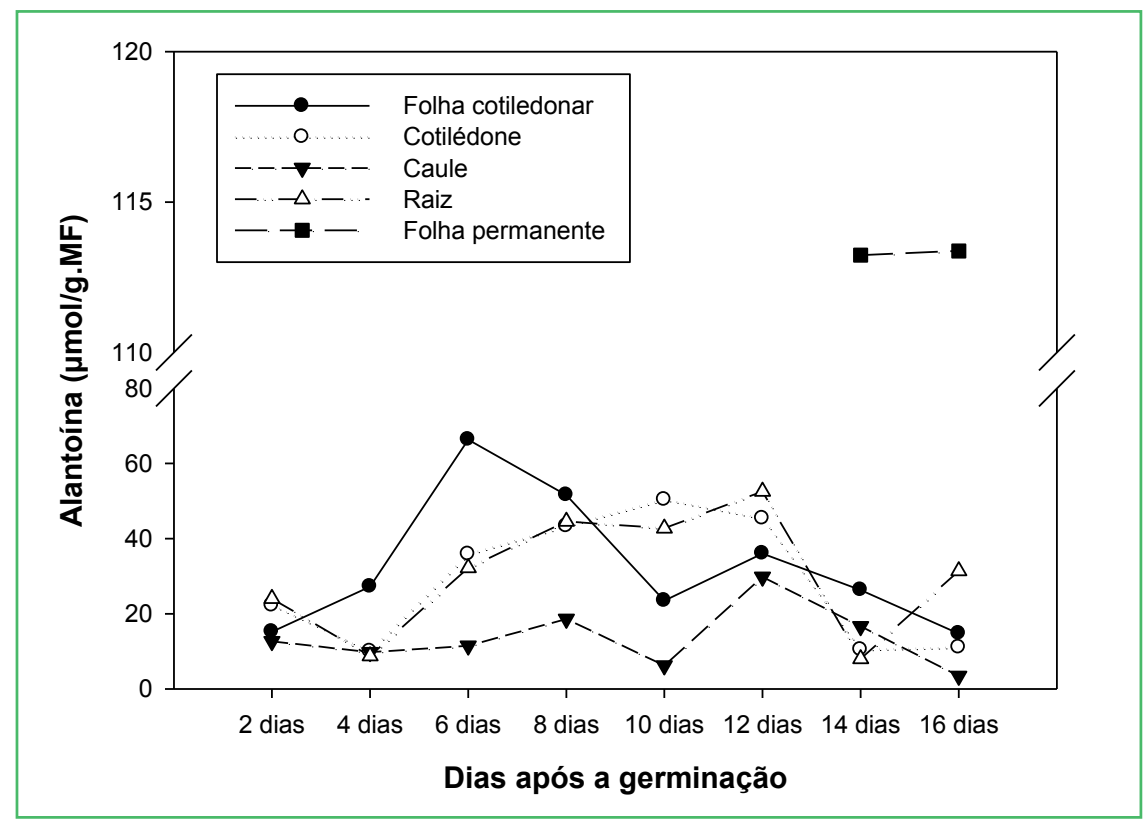




\section{Discussão}

As leguminosas fixam o nitrogênio da atmosfera e transportam estes nutrientes para parte aérea pelo xilema na forma de ureídeos e aminoácidos (AMARANTE; SODEK, 2006; JUSTINO; SODEK, 2013). Ao mesmo tempo, estas plantas transportam nitrato para a parte aérea, embora, em muitos casos, este nutriente ocasione danos à associação simbiótica. Atualmente, tem sido verificado que algumas destas associações são extremamente resistentes à presença do nitrato (CAMARGOS; SODEK, 2010). Sendo assim, como observado no presente estudo, os produtos da fixação biológica do nitrogênio, ureídeos e aminoácidos são satisfatoriamente armazenados nas sementes. Por outro lado, a presença de nitrato demonstra que este nutriente foi absorvido e armazenado em cotilédones desta espécie, o que poderia sugerir que ocorre manutenção da fixação biológica mesmo na presença do nitrato. Todos estes compostos nitrogenados, durante a fase inicial de desenvolvimento, logo após a germinação, mantêm a nutrição da plântula principalmente pela degradação de reservas dos cotilédones que logo em seguida são descartados, quando o sistema radicular da planta passa a suprir as demandas fisiológicas da planta (CARVALHO; NAKAGAWA, 2000). A literatura descreve que o nitrato não é retranslocado via floema, e, portanto sua presença no xilema (folhas) é indicativa de absorção radicular, mas é conhecido que o estímulo da germinação pelo nitrato pode ser associado a um artifício de sobrevivência (BELL et al., 1999). Como não houve fornecimento de nitrato nas fases iniciais de desenvolvimento, a presença deste nos demais tecidos lança uma pergunta sobre a não redistribuição deste íon via floema, embora estudos adicionais devam ser realizados a fim de estudar o metabolismo do nitrato durante o processo de utilização pela plântula.

Os teores de ureídeos foram bastante proeminentes durante os dezesseis dias de experimento, um indicativo da utilização destes compostos para o armazenamento de nitrogênio na semente e de translocação entre as partes da plântula durante o estabelecimento desta espécie. A quantidade de ureídeos encontrada em cotilédones de $C$. brasiliensis no presente experimento foi bastante superior à verificada em sementes de
Phaseolus vulgaris (QUILES et al., 2009). Nos dados encontrados em nosso experimento, verificou-se um aumento dos teores de ureídeos totais em cotilédones até os dez dias após a germinação e, posteriormente, estes valores começaram a diminuir, o que pode estar relacionado à degradação de purinas (TODD et al., 2006) e não só à remobilização das reservas cotiledonares. Por outro lado, Quiles et al. (2009) verificaram uma redução nos teores de ureídeos dos cotilédones no primeiro dia do experimento, atingindo os menores valores no segundo dia, sendo que no terceiro dia os teores começaram a aumentar novamente. Segundo estes autores, este aumento seria produto da síntese de ureídeos durante o estágio inicial de desenvolvimento da plântula. Aumentos nos teores de ureídeos após o início da germinação também foram observados em cotilédones de plântulas de soja, provavelmente devido à conversão de purinas em ureídeos, resultado do processo de senescência dos cotilédones (DURAN; TODD, 2012). Os menores valores encontrados em Phaseolus vulgaries devem-se, em parte, à baixa eficiência da fixação biológica do nitrogênio verificada nesta espécie (FORNASIERI-FILHO et al., 2007), o que normalmente é complementada por nitrogênio combinado adicionado ao meio de cultivo. A concentração dos teores de ureídeos em folhas permanentes foi bastante superior ao verificado em outros órgãos, como folha, caules, cotilédone e folha cotiledonar. $\mathrm{O}$ surgimento da folha permanente parece ter atuado como dreno para parte dos ureídeos presentes nos demais órgãos, cuja concentração diminuiu consideravelmente após os 14 dias.

Alantoína e ácido alantoico são duas formas de ureídeos utilizadas para o transporte de nitrogênio, principalmente em espécies da tribo Phaseolae, sendo no passado, utilizados como mecanismo de avaliação da eficiência da fixação biológica (McCLURE et al., 1980). No caso deste experimento, verificou-se que estes dois compostos foram utilizados no transporte de nitrogênio dos cotilédones para as outras partes da planta e, posteriormente, entre outros órgãos da planta. A vantagem do transporte na forma de alantoína e ácido alantoico reside na eficiência do transporte de nitrogênio em relação aos átomos de carbono que compõem a molécula, pois a razão $\mathrm{N}: \mathrm{C}$ é de $1: 1$ (QUILES et al., 2009). Em C. brasiliensis, com exceção 
do segundo, quarto e décimo dia, verificou-se sempre maiores quantidades de alantoína e ácido alantoico, demonstrando a importância destes compostos na alocação de nitrogênio durante o estabelecimento da espécie. Mas, os teores mais proeminentes de ácido alantoico e alantoína foram verificados aos 14 e 16 dias após a germinação. Os valores são bastante superiores aos encontrados anteriormente, indicando transporte e, possivelmente, síntese em outros órgãos da plântula. A síntese foi demonstrada por Quiles et al. (2009) após a remoção dos cotilédones e a constatação do aumento destes compostos no eixo embrionário sem que nenhum sinal oriundo dos cotilédones promovesse a elevação no conteúdo destes compostos.

Os teores de proteínas apresentaram redução decrescente desde o início da embebição em Caesalpinia peltophoroides (BORGES et al., 2005). O mesmo resultado foi observado por Corte et al. (2006), trabalhando com a mesma espécie. Em Schizolobium parayba, os teores de proteínas mantiveram-se constantes até dois dias após a embebição da semente, reduzindo-se aos quatro e seis dias e aumentando levemente aos oito dias (MAGALHÃES et al., 2010). Por outro lado, em Qualea grandiflora não foram observadas alterações durante o processo de germinação (PAULILO; FELIPPE, 1994). No presente trabalho verificou-se uma redução nos teores de proteínas quando comparados aos valores iniciais, aos dois dias, e os valores verificados aos 16 dias, mas foram verificados dois picos aos oito e doze dias. Estes resultados poderiam sugerir degradação e síntese de proteínas. Entretanto, existe a necessidade de estudos mais aprofundados sobre o metabolismo de proteínas para a obtenção de conclusão satisfatória neste sentido.

As proteínas são importantes fontes de reserva de sementes de leguminosas (TEIXEIRA et al., 1985; SASAKI, 2008). Durante a germinação da semente e a fase inicial de estabelecimento da plântula, as proteínas estocadas são degradadas por proteinases e, depois, transportadas para os outros órgãos da plântula (KIM et al., 2011). Em C. brasiliensis, o transporte de nitrogênio oriundo da degradação dos corpos proteicos em plântulas de $C$. brasilienses não é conhecido ainda, mas, geralmente em leguminosas, a forma predominante são as amidas (asparagina e glutamina), componente encarregado do transporte, e a arginina, aminoácido mais frequentemente encontrado após a mobilização de proteínas de reserva. Em Canavalia ensiformes, foi observado que arginina compunha cerca de $15 \%$ do total de aminoácidos incorporados a proteínas da semente, enquanto que glutamina + glutamato compunham cerca de 23\% (CAMARGOS et al., 2004). No presente trabalho, observamos que os níveis de aminoácidos apresentam contribuição relevante no transporte durante o período inicial de mobilização de reservas cotiledonares, a partir do segundo dia após a germinação permanecendo até o quarto dia após a germinação, e voltando a decair após a mobilização, indicando ser um dos primeiros compostos nitrogenados degradados durante a formação da plântula. Um outro aspecto relevante é que o aporte de aminoácidos e proteínas torna o tecido suscetível à herbivoria, uma vez que na fase inicial são tecidos tenros e de fácil predação. A presença de canavanina nesta fase inicial, concentrando-se nos tecidos da parte aérea (folhas e caule) demonstra ser a estratégia adotada para evitar a predação, uma vez que decaem os níveis aos 10 dias de desenvolvimento. Altas concentrações de canavanina em sementes e em tecidos de plântulas (sete dias de desenvolvimento) foram encontrados por Camargos et al. (2004) para tecidos de Canavalia ensiformes. Por tratar-se de um aminoácido não proteico, análogo de arginina, a presença na fase inicial demonstra o potencial de defesa contra herbivoria; consequentemente, a redução na concentração indica que houve degradação e realocação em outros compostos constituintes ou de transporte.

A partir dos resultados foi possível concluir que:

- Proteínas, ureídeos, aminoácidos e nitrato foram importantes compostos armazenados na semente, podendo ser utilizados como fonte de nitrogênio por esta espécie;

- O aminoácido não-proteíco canavanina foi estocado na semente, indicando ser utilizado como mecanismo de defesa e/ou como forma de armazenamento de nitrogênio na semente;

- Ocorreram aumentos e reduções importantes no conteúdo de ureídeos totais, o que poderia indicar utilização e/ou transporte e/ou síntese nos órgãos vegetais analisados; 
- O armazenamento de nitrato e de produtos da fixação biológica do nitrogênio (ureídeos) indicou que a espécie estudada tem a capacidade de absorver tanto o nitrogênio mineral do solo como o nitrogênio molecular;

- Os aminoácidos foram os compostos nitrogenados mais rapidamente utilizados por esta espécie durante o estabelecimento da plântula.

\section{Referências}

AMARANTE, L.; SODEK, L. Waterlogging effect on xylem sap glutamine of nodulated soybean. Biologia Plantarum, Praha, v. 50, n. 3, p. 405-410, 2006.

BELL, D. T.; KING, L. A.; PLUMMER, J. A. Ecophysiological effects of light quality and nitrate on seed germination in species from Western Australia. Australian Journal of Ecology, Canberra, v. 24, n. 1, p. 2-10, 1999.

BIELESKI, R. L.; TURNER, N. A. Separation and estimation of amino acids in crude plant extracts by thin-layer electrophoresis and chromatography. Analytical Biochemistry, San Diego, v. 17, p. 278-293, 1966.

BORGES, E. E. L.; REZENDE, S. T.; BORGES, R. C. G.; PEREZ, S. C. J. G. A. Caracterização de alfagalactosidase e sua relação com germinação das sementes de Caesalpinia peltophoroides (Leguminosae Caesalpinioideae). Revista Árvore, Viçosa, v. 29, n. 4, p. 525-533, 2005.

BRADFORD, M. M. A rapid and sensitive method for quantitation of microgram quantities of protein utilizing the principle of proteindye binding. Analytical Biochemistry, San Diego, v. 72, p. 248254, 1976.

BUCKERIDGE, M. S.; AIDAR, M. P. M.; SANTOS, H. P.; TINÉ, M. A. S. Acúmulo de reservas. In: FERREIRA, A. G.; BORGHETTI, F. (Ed.). Germinação: do básico ao aplicado. Porto Alegre: Artmed, 2004. p. 31-50.

BUCKERIDGE, M. S.; TINÉ, M. A. S.; SANTOS, H. P. dos; LIMA, D. U. Polissacarídeos de reserva de parede celular em sementes. Estrutura, metabolismo, funções e aspectos ecológicos. Revista Brasileira de Fisiologia Vegetal, Campinas, v. 12, Edição Especial, p. 137-162, 2000.

CAMARGOS, L. S.; AGUIAR, L. F.; AZEVEDO, R. A. Variation in the amino acid concentration during development of Canavalia ensiformes. Biologia Plantarum, Praga, v. 48, p. 309-314, 2004.

CAMARGOS, L. S.; SODEK, L. Nodule growth and nitrogen fixation of Calopogonium mucunoides L. show low sensitivity to nitrate. Symbiosis, Philadelphia, v. 51, p. 167-174, 2010.

CARVAlHO, N. M.; NAKAGAWA, J. Sementes: ciência, tecnologia e produção. 3. ed. Campinas: Fundação Cargill, 2000. $424 \mathrm{p}$.

CATALDO, D. A.; HAROON, M.; SCHRADER, L. E.; YOUNGS, V. L. Rapid colorimetric determination of nitrate in plant tissue by nitration of salicylic acid. Communications in Soil Science and Plant Analysis, Philadelphia, v. 6, p. 71-80, 1975.
CORTE, V. B.; BORGES, E. E. de L.; PONTES, C. A.; LEITE, I. T. de A.; VENTRELLA, M. C.; MATHIAS, A. de A. Mobilização de reservas durante a germinação das sementes e crescimento das plântulas de Caesalpinia peltophoroides Benth. (LeguminosaeCaesalpinioideae). Revista Árvore, Viçosa, v. 30, n. 6, p. 941-949, 2006.

CRAWFORD, N. M.; GLASS, A. D. M. Molecular and physiological aspects of nitrate uptake in plants. Trends in Plant Science, Oxford, v. 3, n. 10, p. 389-395, 1998.

DURAN, V. A., TODD, C. D. Four allantoinase genes are expressed in nitrogen-fixing soybean. Plant Physiology and Biochemistry, Paris, v. 54, p. 149-155, 2012.

FORNASIERI-FILHO, D.; XAVIER, M. A.; LEMOS, L. B.; FARINELLI, R. Resposta de cultivares de feijoeiro comum à adubação nitrogenada em sistema de plantio direto. Científica, Jaboticabal, v. 35, n. 2, p. 115-121, 2007.

JUSTINO, G. C.; SODEK, L. Recovery of nitrogen fixation after short-term flooding of the nodulated root system of soybean. Journal of Plant Physiology, Jena, v. 170, n. 3, p. 235-241, 2013. KIM, R. T.; CHOI, U-K.; RYU, H. R.; LEE, S. J.; KWON, O-S. Mobilization of storage proteins in soybean seed (Glycine max L.) during germination and seedling growth. Biochimica et Biophysica Acta, Amsterdam, v. 1814, p. 1178-1187, 2011.

LAM, H. M.; CHIAO, Y. A.; LI, M. W.; YUNG, Y. K.; JI, S. Putative nitrogen sensing systems in higher plants. Journal of Integrative Plant Biology, Beijing, v. 48, n. 8, p. 873-888, 2006.

MAGAlhães, S. M.; BORGES, E. E. L.; BERGER, A. P. A. Mobilização de reservas no eixo embrionário e nos cotilédones de Schizolobium parayba (Vell.) S. F. Blake durante a germinação. Ciência Florestal, Santa Maria, v. 20, n. 4, p. 589-595, 2010.

McCLURE, P. R.; ISRAEL, D. W.; VOLK, R. J. Evaluation of the relative ureide content of xylem sap as an indicator of $\mathrm{N}_{2}$ fixation in soybeans. Plant Physiology, Rockville, v. 66, n. , p. 720-725, 1980.

PAULILO, M. T. S.; FELIPPE, G. M. Contribuição dos cotilédones e participação de matérias durante o crescimento inicial de Qualea grandiflora Mart. (Vochysiaceae). Revista Brasileira de Botânica, São Paulo, v. 17, n. 2, p. 87-91, 1994.

QUILES, F. A.; RASO, M. J.; PINEDA, M.; PIEDRAS, P. Ureide metabolism during seedling development in French bean (Phaseolus vulgaris). Physiologia Plantarum, Lund, v. 135, n. 1, p. 19-28, 2009.

ROSENTHAL, G. A. Preparation and colorimetric analysis of L-canavanine. Analytical Biochemistry, San Diego, v. 77, p. $147-$ $151,1977$.

SASAKI, M. Lípideos, carboidratos e proteínas de sementes de leguminosas do cerrado. 2008. 75 f. Dissertação (Mestrado em Botânica) - Universidade de São Paulo, São Paulo, 2008.

SODRÉ-FILHO, J.; CARDOSO, A. N.; CARMONA, R.; CARVALHO, A. M. Fitomassa e cobertura do solo de culturas de sucessão ao milho na Região do Cerrado. Pesquisa Agropecuária Brasileira, Brasília, v. 39, n. 4, p. 327-334, 2004.

TEIXEIRA, J. P. F.; SPOLADORE, D. S.; BRAGA, N. R.; BULISANI, E. A. Composição Química de grãos de feijão-guandu cultivar Kaki. Bragantia, Campinas, v. 44, n. 1, p. 457-463, 1985.

TODD, C. D.; TIPTON, P. A.; BLEVINS, D. G.; PIEDRAS, P.; PINEDA, M.; POLACCO, J. C. Update on ureide degradation in 
legumes. Journal of Experimental Botany, Oxford, v. 57, n. 1, p. 5-12, 2006.

VITOUSEK, P. M.; HOWARTH, R. W. Nitrogen limitation on land and in the sea - how can it occur. Biogeochemistry, Dordrecht, v. 13, n. 2, p. 87-115, 1991.

VOGELS, G. D.; VAN DER DRIFT, C. Differential analyses of glyoxylate derivates. Analytical Biochemistry, San Diego, v. 33, n. 1, p. 143-157, 1970.

YEMM, E. W.; COCKING, E. C. The determination of amino acids with ninhydrin. Analyst, Cambridge, v. 80, n. 948, p. 209213, 1955. 